\title{
O ARQUIVO INIMIGO RUMOR, ESCOLHAS E AFINIDADES
}

\author{
Elisa Helena Tonon ${ }^{1}$
}

Ler, escrever, não duvidamos que tais palavras sejam solicitadas a ter, em nosso espírito, um papel muito diferente daquele que ainda tinham no começo do século $X X$ : isso é evidente, qualquer rádio, qualquer tela, nos advertem disso e, mais ainda esse rumor em volta de nós, esse zumbido anônimo e contínuo em nós, essa maravilhosa fala inesperada, ágil, incansável, que nos dota a cada momento de um saber instantâneo, universal, e faz de nós a mera passagem de um movimento em que cada um é sempre, de antemão, trocado por todos.

Blanchot, O livro por vir

\section{Revista: coleção, reunião, arquivo}

No verbete "O colecionador" de suas Passagens, Walter Benjamin nos diz que "talvez o motivo mais recôndito do colecionador possa ser circunscrito da seguinte forma: ele empreende a luta contra a dispersão. O grande colecionador é tocado bem na origem pela confusão, pela dispersão em que se encontram as coisas no mundo"2.

Podemos pensar que, entre outras coisas, é este desejo de evitar a dispersão que motiva diversos poetas brasileiros, a partir da década de 90 , a iniciar a publicação de revistas de literatura e poesia ${ }^{3}$. O esforço depreendido

\footnotetext{
${ }^{1}$ Mestranda do curso de Pós-Graduação em Literatura da Universidade Federal de Santa Catarina, desenvolve pesquisas principalmente nos seguintes temas: poesia, literatura, periodismo cultural e América Latina. O presente trabalho contou com o apoio do CNPq.

${ }^{2}$ BENJAMIN, Walter. Passagens. (Org.: Wille Bolle) São Paulo: IMESP, 2006. p.245.

3 Sérgio Cohn com Azougue, em 1996; Carlito Azevedo com Inimigo rumor em 1997; Ricardo Corona, Rodrigo Garcia Lopes, Ademir Assunção e Eliana Borges, em 1998 com Medusa; ainda em 1998, Tarso M. de Melo com Monturo; Ademir Demarchi com Babel em 2000; Régis Bonvicino em 2001 com Sibila; Rodrigo Garcia Lopes, Ademir Assunção e Marcos Losnak com Coyote em 2002; Eduardo Sterzi e Tarso de Melo, com Cacto, também em 2002; Chico Mattoso e Paulo Werneck com Ácaro em 2002; Ricardo Corona e Eliana Borges, em 2004 com Oroboro e por
} 
nesta realização, além de combater o risco da dispersão, parece motivado pelo desejo de demonstrar quão equivocado é o "discurso do fim" que ainda atinge a poesia $^{4}$, as revistas assim seriam mais um atestado para a vitalidade e diversidade da poesia brasileira.

Pretendo pensar estas revistas aqui, como procedimento, operações de leitura que possuem um estreito (estranho) vínculo com a memória. Elas funcionam como um (no) arquivo, que, como tão bem nos ensina Derrida, é o dispositivo que simultaneamente reúne e interpreta, institui e conserva. O arquivo tem sua existência garantida pelo risco, pela ameaça de finitude, de apagamento, de destruição, que coexiste com o impulso de guardar, economizar, acumular, pôr em reserva.

Delegado aos cuidados do arconte - que o reúne, conserva e interpreta -, o arquivo é não só o local, o exterior, a morada de um "conteúdo arquivável passado" 5 , mas também o que determina "a estrutura do conteúdo arquivável em seu próprio surgimento e em sua relação com o futuro. O arquivamento tanto produz quanto registra o evento. É também nossa experiência política dos meios chamados de informação" .

\section{Festa ou velório?}

O primeiro número da revista de poesia Inimigo rumor sai em 1997 e não explicita projeto algum, porém publica a 'antológica' carta de João Cabral de Melo Neto a Clarice Lispector, em que se discute a elaboração de uma revista que

último; Angélica Freitas, Fabiano Calixto, Marília Garcia e Ricardo Domeneck, com Modo de Usar \& Co., em 2007. Ou seja, entre outras diversas publicações destinadas à literatura circulando no mesmo período, é possível destacar mais de uma dezena delas que são (foram) elaboradas principalmente por poetas e destinadas principalmente à poesia.

${ }^{4}$ Como o desejo que impulsiona Heloísa Buarque de Hollanda a se re-lançar na tarefa de montar uma antologia, com "Esse poetas - Uma antologia dos anos 90": "Essa não é a primeira vez. O fato é que, diante de qualquer formação de consenso a respeito de quedas de vitalidade na produção cultural, sinto-me impelida a organizar uma antologia de novos poetas". Hollanda. Heloísa Buarque de. Esses poetas: uma antologia dos anos 90. Rio de Janeiro: Aeroplano Editora, 2001. p.9.

${ }^{5}$ DERRIDA, Jacques. Mal de arquivo: uma impressão freudiana. Trad.: Claudia de Moraes Rego. Rio de Janeiro: Relume Dumará, 2001, p.28.

${ }^{6}$ Idem, p.29. 
deveria se chamar "Antologia". Este projeto idealizado por João Cabral, em fins da década de 40, ganha vida meio século depois com edição do poeta Carlito Azevedo, no Rio de Janeiro. A revista que se apresenta enxuta, sóbria, em formato-livro, sem ilustrações ou hierarquia entre os textos que veicula, tem sua diretriz já dada na carta em questão: "qualquer coisa fora do tempo e do espaço um pouco como nós vivemos. O fim verdadeiro da revista será o de começar a escolher o que presta de todos nós. Qualquer coisa como um balanço de antes do fim de ano, um balanço dos fevereiros que nós todos somos"7.

Pouco tempo após seu surgimento, Inimigo rumor é saudada, com uma mescla de satisfação e incômodo, por Ítalo Moriconi em texto intitulado "Qualquer coisa fora do tempo e do espaço (poesia, literatura, pedagogia da barbárie)"8. O crítico inicia o ensaio pedindo licença para se colocar num lugar paradoxal por onde se move "o crítico literário, o escritor profissional, o poeta cultivado, o pedagogo das letras", lugar tensionado por:

De um lado, as tradicionais hierarquias e divisões do saber, o próprio saber literário como aprendizado estético, exercício da capacidade mesma de hierarquizar valores. De outro, os efeitos perversos, proliferantes, disruptivos, horizontalizadores, de saberes inacabados, incompletos, grosseiros, arrogantes no seu desconhecer a História passada, mas fulgurantes como emergências na história presente. ${ }^{9}$

Deste lugar cindido, Moriconi relata seus sentimentos diante do fenômeno por ele chamado de "volta ao literário" ou "nova tendência à sofisticação literária na poesia brasileira dos anos 80 e 90", que seria uma reação, ou uma tentativa de restauração diante da "barbárie" instaurada no campo da literatura. Com este tom pessoal e íntimo, o texto segue para se deter sobre a revista Inimigo rumor:

É a restauração literária que me causa terremotos de sensações ambíguas. E começo por um lugar bem próximo de mim, física e

\footnotetext{
${ }^{7}$ MELO NETO, João Cabral de. In Inimigo rumor. Rio de Janeiro, Sette Letras, 1997, $n^{\circ}$ 1. p.30, grifo meu.

${ }^{8}$ MORICONI, Ítalo. "Qualquer coisa fora do tempo e do espaço (poesia, literatura. Pedagogia da barbárie)". In ANDRADE, Ana Luiza et al (orgs.). Leituras do ciclo. Florianópolis: ABRALIC: Chapecó: Grifos, 1999.

${ }^{9}$ Idem, p.75.
} 
afetivamente. Um lugar carioca de resistência e restauração do literário, agenciado por grupo com quem mantenho as melhores relações pessoais e de quem não posso reclamar nada, pois me abriu generosamente suas páginas tanto para versos quanto para o exercício da resenha. Todo lugar criado é abertura de espaço. E toda pessoa que escreve por profissão, num dos quatro papéis acima mencionados, vive em busca de espaço. Espaço para publicação é ar, é água, é condição de vida para quem lida profissionalmente nas esferas da produção e da circulação de letra. O lugar tão próximo a mim, e em relação ao qual confesso mixed feelings, é o da revista de poesia Inimigo rumor ${ }^{10}$.

O escritor então, de um lado, comemora a chegada da revista no cenário da década de 90, paralelamente a outras publicações (destaca a coleção de poesia da editora Sette Letras, as revistas Poesia Sempre, Cult e Bravo) que dariam vez e voz a poesia que estava "florescendo". Por outro lado, neste momento quando os três primeiros números da revista haviam sido publicados e o quarto estava em vias de ser lançado, a revista gera insatisfação quando o autor constata a presença maciça de poetas já consagrados, "enquanto antologia, a revista trabalha no sentido de fixar e consolidar a posição de alguns poetas importantes em fase madura" ${ }^{11}$, dedicando seu espaço quase exclusivamente "à poesia literária".

Como conseqüência, o crítico segue neste entre: tanto reafirma a necessidade de uma atenção à "literatura literária" (a exemplo de João Cabral, Guimarães Rosa e Clarice Lispector), que representaria certa defesa contra a barbárie pós-moderna; como se reconhece em um tempo no qual "o literário só existe e só faz sentido no atrito com o não-literário", e reivindica a necessidade de "pedagogias horizontalizadoras".

O texto é sintomático, e dez anos depois ${ }^{12}$, no percurso traçado por Inimigo, pode-se facilmente detectar uma unidade tanto no aspecto visual, que ainda dá ao texto exclusividade na página, não carrega informações bibliográficas sobre autores e manteve seu formato-livro; quanto na elaboração e desenvolvimento do projeto pelo mesmo editor, que apesar de ter sempre ao seu lado um conselho editorial, é o "guardião" deste arquivo, seu arconte.

\footnotetext{
${ }_{11}^{10}$ Idem, p.76.

${ }^{11}$ Idem, p.77.

${ }^{12}$ Este ensaio é um estudo dos números 1 a 19 de Inimigo rumor.
} 
A razão da queixa de Moriconi, o "insuficiente espaço exclusivamente literário", parece não estar mais lá. A reunião de nomes da "literatura literária" foi a estratégia de sobrevivência da revista em sua fase inicial, quando teria a necessidade de responder a uma "economia arquival"13 ${ }^{13}$, justificando o emprego de uma "pesada máquina tipográfica", tinta, papel enfim; a revista deveria oferecer uma poesia nobre, de valor, que fosse digna do investimento feito no arquivo que cria e, especialmente, em sua leitura. É dessa forma que temos o primeiro número inaugurado pelo poema "Renga em New York" de Haroldo de Campos, seguido de poemas de Sebastião Uchoa Leite, Francisco Alvim, Armando Freitas Filho, Ronald Polito, Lezama Lima, Paul Valéry, Max Jacob, Saint-John Perse.

Essa economia (ou política?) rege a revista até o seu $10^{\circ}$ número, quando começa a dar espaço à poesia portuguesa e na seqüência passa a ser uma publicação luso-brasileira, travando um diálogo com poetas e críticos portugueses nos números 11 a 15. Em sua fase consecutiva, a revista volta a ser exclusivamente brasileira, e então vemos crescer a quantidade de autores brasileiros novos em comparação com os demais autores, como é o caso de Ricardo Domeneck, jovem poeta e crítico que, a partir do número 16, passa a integrar o grupo de colaboradores assíduos de Inimigo rumor, com poemas e ensaios críticos $^{14}$. Isso pode ser entendido como uma decorrência da consolidação da revista no cenário da poesia brasileira, pois ela já não teria a necessidade de justificar sua existência com a publicação de nomes consagrados, e passa então a dar cada vez mais espaço para aqueles "que prestam", retomando as palavras de João Cabral, na produção de poesia e crítica no início de milênio.

Por outro lado, existem nomes que figuram na revista desde o início com uma freqüência considerável: Marcos Siscar, Aníbal Cristobo, Heitor Ferraz e Zuca Sardan ${ }^{15}$. Os três primeiros, poetas e críticos jovens, que iniciaram suas

\footnotetext{
${ }^{13}$ DERRIDA, Jacques. Mal de arquivo: uma impressão freudiana. Trad.: Claudia de Moraes Rego. Rio de Janeiro: Relume Dumará, 2001. p.18.

14 Domeneck soma 7 colaborações entre os números 16 e 19.

${ }^{15}$ Entre poemas e ensaios, Marcos Siscar possui 20 colaborações; Aníbal Cristobo contabiliza 26; Heitor Ferraz soma 32; e Zuca Sardan teve 20 poemas seus publicados ao longo dos 19 números da revista.
} 
publicações na década de 90, sendo que Siscar e Cristobo publicam na revista antes de terem seus livros editados. Já o caso de Zuca Sardan é bastante específico, nascido em 1933, começa a publicar ainda na década de 70, participa da antologia 26 poetas hoje, organizada por Heloísa Buarque de Hollanda (assim como Eudoro Augusto e Francisco Alvin, também nomes assíduos na revista). 0 caso de Sardan é específico não apenas por pertencer à outra geração, mas principalmente por sua poesia, que inclui desenho e elementos visuais, além de estar baseada na ironia e no humor, caso único nas páginas da revista.

\section{Memória e esquecimento}

A questão da memória está implicada nesta revista que se apresenta como uma seleção de textos memoráveis, antológicos. A escolha dos elementos que montam esta antologia é uma operação de assinalamento e de rasura. $\mathrm{O}$ arquivo está sempre acompanhado de seu mal, a pulsão de morte e destruição que the é inerente. História e memória se edificam sobre os fundamentos do esquecimento. Para acumular o inesquecível há que se esquecer outras coisas "não interessantes".

Com isso somos incitados a "des-ler" esta revista-arquivo, buscando nela justamente o que falta, o que se apresenta como falta, numa tentativa de se aproximar da proposta de Benjamin, de ler a história a contrapelo. Há duas ausências em Inimigo rumor que merecem atenção. A primeira é a de Paulo Leminski, poeta que teve sua produção em diálogo com concretistas e marginais e é um nome chave para outras revistas contemporâneas, como Medusa, Monturo e Coyote. Em Monturo, Leminski aparece já no título, pensado para um de seus livros e depois substituído, foi escolhido para nomear a revista que teve apenas 3 números publicados entre 1998 e 1999. Editada por Tarso M. de Melo, Monturo incluía no seu conselho editorial Regis Bonvicino, que será depois editor de Sibila, e também Fabiano Calixto, que hoje edita Modo de usar \& Co. Além do título, a revista homenageou Leminski publicando uma reunião de trechos de entrevistas e 
um depoimento de Bonvicino. Em Medusa e Coyote encontramos dossiês sobre o poeta paranaense, com entrevistas e textos seus, além de ser um nome freqüentemente citado por ensaios e entrevistas de outros autores nestes periódicos. No entanto, em Inimigo rumor, não encontramos nem poemas, nem textos de ou sobre Leminski.

Outra ausência no arquivo Inimigo rumor é Roberto Piva, poeta que de fato ficou à margem do circuito em seu período de atuação, mas que é resgatado pela revista Azougue, lançada em 1996 por Sérgio Cohn. Há poemas de Piva também em Medusa, e em Coyote, que publica um dossiê sobre o poeta no número 6.

Se vislumbrar um perfil para Inimigo contemplando a vastidão e a diversidade daquilo que ela reúne é uma tarefa complicada, alguns traços vão ficando nítidos ao nos determos sobre estes apagamentos. Enquanto Leminski e Piva são esquecidos por Inimigo, recebem destaque justamente em revistas que desenvolvem um caminho alternativo: enfatizam elementos visuais, privilegiam poéticas ligadas ao surrealismo, à poesia beat norte-americana e à etnopoética. Da mesma maneira, os editores-poetas Sérgio Cohn, Ricardo Corona, Ademir Assunção, Marcos Losnak não estão presentes em Inimigo rumor, à exceção de Rodrigo Garcia Lopes, editor de Medusa e Coyote, que aparece com três poemas.

Estas ausências, de algum modo, são confirmadas (ou justificadas) no editorial do número 16, momento de transição, quando a revista completa 8 anos e encerra a parceria com os portugueses, o editor aproveita para reafirmar certas propostas e fazer um balanço do trajeto percorrido:

\footnotetext{
As revistas de poesia em atividade valem por aquilo que elas ajudam a reconhecer e provocar no cenário poético. Por isso, o sentido de uma revista só é dado a posteriori, de acordo com uma determinada leitura da poesia do presente e do papel que desempenham seus periódicos.

Inimigo rumor entra em seu oitavo ano fiel às propostas de abertura que a moviam desde o início. ${ }^{16}$
}

Neste editorial, as propostas que eram implícitas até então, são claramente enumeradas $^{17}$, No item b), lemos:

\footnotetext{
${ }^{16}$ Editorial, Inimigo rumor. Rio de Janeiro: 7Letras, 2005, n 16, p.5. Grifos do autor.
} 
Uma breve consulta em nossos sumários revelará que a revista assumiu, sem qualquer estardalhaço teórico ou qualquer sentimento de culpa, a herança modernista recente, incorporando os poetas concretos, os marginais dos anos 70 (Francisco Alvin, Zuca Sardan, Ana Cristina César, Eudoro Augusto e Cacaso, em especial), além de autores independentes como Ferreira Gullar e Sebastião Uchoa Leite, com a diferença fundamental de ler a todos eles não mais por suas oposições, já bastante conhecidas, mas sim "por suas intersecções"

De algum modo, aqui fica evidente o motivo das ausências de Leminski e Piva: eles não pertenceriam nem ao grupo dos "marginais" e nem ao dos "autores independentes" eleitos. Este também parece ser o caso de Chacal, que não pertence aos "marginais" que a revista elege: o poeta tem apenas um poema publicado em Inimigo, como uma exceção que confirma a regra.

Borges já apontava a necessidade do esquecimento para a realização de ações práticas e corporais, como perceber, ver e ouvir:

El hecho mismo de percibir, de atender, es de orden selectivo: toda atención, toda fijación de nuestra conciencia, comporta una deliberada omisión de lo no interesante. Vemos y oímos a través de recuerdos, de temores, de previsiones. En lo corporal, la inconsciencia es una necesidad de los actos físicos. Nuestro cuerpo sabe articular este difícil párrafo, sabe tratar con escaleras, con nudos, con passos a nível, con ciudades, con ríos correntosos, con perros, sabe atravesar una calle sin que nos aniquile el tránsito, sabe engendrar, sabe respirar, sabe dormir, sabe tal vez matar: nuestro cuerpo, no nuestra inteligencia. Nuestro vivir es una serie de adaptaciones, vale decir, una educación del olvido. ${ }^{19}$

O esquecimento, então, aparece como fundamento de ações vitais, como um conhecimento do corpo, não da inteligência. Isso conduz a pensar as escolhas deste 'arconte' como algo que está fora do âmbito do juízo estético ou da decisão crítica racional. A escolha estaria pautada por outras forças, por uma 'economia dos afetos'.

17 a) abrir espaço para os poetas estreantes; b) divulgar material inédito de poetas e ensaístas brasileiros já estabelecidos; c) disponibilizar poemas e ensaios estrangeiros que aumentem nosso repertório de poesia e crítica em português.

${ }_{18}^{18}$ Editorial, Inimigo rumor. Rio de Janeiro: 7Letras, 2005, no 16, p.5. Grifos do autor.

19 BORGES, Jorge Luis. "La postulación de la realidad" in Obras completas: 1923-1949. Buenos Aires: Emecé editores, 2007. p.255. 


\section{Escolhas, afinidades e a ameaça do fim}

Os dados evidenciam como esta coleção constitui (é constituída por) uma rede, uma trama de referências e textos acumulados. Entretanto, é preciso distinguir arquivo e coleção. Esta, como Benjamin explica nas Passagens, é armada a partir de elos e semelhanças: o colecionador "reúne as coisas que são afins; consegue, deste modo, informar a respeito das coisas através de suas afinidades ou de sua sucessão no tempo". À figura do colecionador, ainda em busca de uma totalidade, o autor alemão contrapõe a do alegorista, que não objetiva entender as coisas por seus elos e propriedades, mas as retira de seu contexto, pois "representam apenas verbetes de um dicionário secreto, que revelará seus significados ao iniciado, [...] sendo que uma delas pode tanto menos substituir a outra que nenhuma reflexão permite prever o significado que a meditação pode reivindicar para cada uma" ${ }^{20}$.

Descobre-se então que a alegoria está próxima do arquivo, pois não possui o caráter da ordem e da organização que rege a coleção (e a biblioteca). No entanto, partilha com a coleção a atitude acumulativa, que Walter Benjamin, citando Paul Morand, associa à morte: "A necessidade de acumular é dos sinais precursores da morte, tanto nos indivíduos quanto nas sociedades. Ela surge em seu estado agudo nos períodos pré-paralíticos" ${ }^{21}$.

Ora, então este ímpeto de organizar revistas/arquivos, que vêm acometendo diversos poetas brasileiros nos últimos anos, em especial Carlito Azevedo, pode ser um indício de paralisia ou morte. Mas morte de quê? Da poesia? E não são as revistas justamente o oposto, o índice da vitalidade da produção poética?

O poeta francês Michel Deguy, em seu texto "Situação", refletindo sobre a condição e o lugar da poesia em tempos pós-modernos, destaca que, assim como

\footnotetext{
${ }^{20}$ BENJAMIN, Walter. "O colecionador" in Passagens. (Org.: Wille Bolle) São Paulo: IMESP, 2006. p.245.

${ }^{21}$ Idem, p.242.
} 
outros fenômenos, a poesia assiste à diminuição de sua importância no campo da literatura, fato que "pode ser observado quando consente muito facilmente, excessivamente de bom grado em inserir-se em antologias temáticas, escolares ou cronológicas, etc. Uma revista de poesia, igualmente, não é um florilégio?”22.

Voltamos à questão já apontada por Moriconi, a instauração da "barbárie" no campo da literatura e principalmente da poesia, que tem seu espaço e seu impacto na vida cultural cada vez mais reduzidos. Paralelamente a isso, as publicações de livros, revistas e antologias aumentam em quantidade impressionante, fenômeno que não se restringe ao Brasil ${ }^{23}$.

Maurice Blanchot refletiu sobre esta angústia do desaparecimento da literatura em O livro por vir. Quanto à espantosa e freqüente pergunta "para onde vai a literatura?", Blanchot afirma: "a literatura vai em direção a ela mesma, em direção à sua essência, que é o seu desaparecimento" ${ }^{24}$. E retoma a famosa frase de Hegel, que em plena efervescência do romantismo já detectava o fim da arte: "A arte é, para nós, coisa do passado". Esta estranha constatação seria já um desdobramento da impossibilidade de ler a arte como resultado direto de experiências subjetivas, que carregariam algo de absoluto ou essencial:

precisamente, a essência da literatura escapa a toda determinação essencial, a toda afirmação que a estabilize ou mesmo que a realize; ela nunca está ali previamente, deve ser sempre reencontrada ou reinventada. Nem mesmo é certo que a palavra "literatura" ou a palavra "arte" correspondam a algo de real, de possivel ou de importante. ${ }^{25}$

\footnotetext{
22 DEGUY, Michel. "Situação" in Inimigo rumor n¹1, p.25.

${ }^{23}$ Como demonstram os ensaios "Can poetry matter?", de Dana Gioia, sobre a cena poética nos EUA. In: The Atlantic Monthly, May 1991. Disponível em: http://www.danagioia.net/essays/ecpm.htm,; "Os poetas sem qualidades na poesia portuguesa recente" de Ida Ferreira Alves, In Poéticas do olhar e outras leituras de poesia. p.217-227; "Situação" de Michel Deguy, in Inimigo rumor n¹1, p.25; "Notas sobre a recente poesia Argentina e suas antologias" de Ana Porrúa, In Babel, n5; "Da poesia", texto da poeta Ingeborg Bachmann, que já em 1960 detectava alguma efervescência na poesia alemã: "Há escritos suficientes, [...] há antologias, publicadas mensalmente em cada revista, e há volumes de poemas" BACHMAN, Ingeborg. "Da poesia" In Inimigo rumor, n¹7. p.94.

${ }^{24}$ BLANCHOT, Maurice. O livro por vir. Trad.: Leyla Perrone-Moisés. São Paulo: Martins Fontes, 2005. p.285.

${ }^{25}$ Idem, p.294.
} 
Se a essência própria da literatura é seu desaparecimento, não há sobressalto quando se conclui que a busca pela arte é uma busca do que escapa, do que não está e, por fim, é uma perseguição da não-arte ${ }^{26}$.

Giorgio Agamben pensa a problemática da "não-arte" ao se deter sobre o julgamento estético, no texto "Les jugements sur la poésie ont plus de valeur que la poésie" 27 . O filósofo italiano nos diz que para o homem moderno, a obra de arte é um convite não à fruição e à satisfação dos sentidos, mas sim ao exercício do juízo e do gosto crítico, o que para nós teria tanto ou mais valor que a própria arte.

Esta é a experiência espontânea e natural de todos que, diante de uma obra de arte (ou poema), nos perguntamos primeiramente se o que vemos é "arte verdadeira" ou "arte falsa". A reflexão sobre o belo como objeto do juízo estético conduz Agamben às conclusões de Nietzsche em Crepúsculo dos ídolos: cada vez que o juízo estético tentou determinar o que seria o belo, ele não conseguiu precisar o belo, mas apenas a sua sombra, "como si el verdadero objeto no fuese tanto lo que es el arte, como lo que no es: no el arte, sino el no-arte" ${ }^{28}$. Este juízo estético é o instrumento do qual necessitamos para conhecer a obra de arte e que, no entanto, "no sólo no nos permite penetrar en su realidad, sino que, remitiéndonos continuamente a aquello que es outra cosa con respecto a ella, nos presenta esta realidad como una sencilla y pura nada". Tanto a apreciação da arte começa com o esquecimento da arte, propõe Agamben, quanto o juízo estético inicia precisamente com o esquecimento de suas origens.

E talvez seja justamente o que temos assistido com o fenômeno das revistas: a morte (ou esquecimento) da poesia enquanto artefato essencialmente artístico. A poesia e a literatura também estariam marcadas por este paradoxo estético a que Kant não soube responder: como são possíveis juízos estéticos a priori? Em busca de definir o que seria o fundamento do juízo estético (o belo), Kant só pode chegar a um princípio supra-sensível e subjetivo, indeterminado e

\footnotetext{
${ }^{26}$ Idem, p.294.

27 AGAMBEN, Giorgio. El hombre sin contenido. Trad.: Eduardo Margaretto Korhmann. Barcelona, Ediciones Áltera, 1998. p.69-87.

${ }^{28}$ Idem, p.72.
} 
místico, que não chega a definir nada. Ao se deparar com esta aporia, a arte moderna optou por sair da dimensão do estético.

$\mathrm{Na}$ literatura do presente, isso se manifesta com a afirmação de um "querer fazer" que inclui o abandono da arte, em detrimento de um "fazer artístico" propriamente dito ${ }^{29}$. Frente à produção contemporânea, o tradicional mecanismo do juízo estético que media a arte pelo seu oposto, não parece obter resultados. De outro lado, a arte, ao tomar consciência de sua sombra, acolhe em si a sua negação e ultrapassa a distância que a separou da crítica, ela mesma se torna reflexão crítica sobre a arte e seus limites ${ }^{30}$.

Este 'querer artístico' impessoal, que Benjamin percebeu em sua análise das obras do barroco e do expressionismo ${ }^{31}$, é retomado por Mario Perniola como um neo-pathos, um ponto de convergência entre "um estado de indiferença, de não participação, de falta de compromisso subjetivo" e um impulso ao atuar e ao falar que não pertence intimamente a nenhum sujeito ${ }^{32}$.

A apatia e a indiferença são tonalidades emotivas características de um tempo saturado de memória. Tempo do déja vù, em que lembrança e percepção coexistem no instante presente. Conforme estudo de Paolo Virno ${ }^{33}$, o déja vù se manifesta sob duas formas: "falso reconhecimento" e "recordação do presente". Enquanto a primeira reconhece em cada ato presente um ato passado já realizado; a segunda vê a coincidência de percepção e memória como uma coexistência do presente real com um passado virtual, a memória aqui é memória de um "passado em geral", um antes indeterminável, que segue acompanhando o

${ }^{29}$ SCRAMIN, Susana. Literatura do presente: história e anacronismo dos textos. Chapecó: Argos, 2007. p.15

${ }^{30}$ AGAMBEN, Giorgio. El hombre sin contenido. Trad.: Eduardo Margaretto Korhmann. Barcelona, Ediciones Áltera, 1998. p.84.

31 "Como o expressionismo, o Barroco é menos a era de um fazer artístico, que de um inflexível querer artístico. É o que sempre ocorre nas chamadas épocas de decadência. A realidade mais alta da arte é a obra isolada e perfeita. Por vezes, no entanto, a obra acabada só é acessível aos epígonos. São os períodos de "decadência" artística, de "vontade" artística. [...] É nesse querer que se funda a atualidade do Barroco, depois do colapso da cultura clássica alemã. A isso se acrescenta a busca de um estilo lingüístico violento, que esteja à altura da violência dos acontecimentos históricos". BENJAMIN, Walter. Origem do drama barroco alemão. Trad.: Sérgio Paulo Rouanet. São Paulo: Brasiliense, 1984. p.77.

32 PERNIOLA, Mario. Enigmas: egípcio, barroco y neo-barroco em la sociedad y el arte. Trad.: Francisco Javier García Melenchón. Murcia: Cendeac, 2003. p.116.

${ }_{33}$ VIRNO, Paolo. El recuerdo del presente: ensayo sobre el tiempo historico. Trad.: Eduardo Sadier. Buenos Aires, Paidós, 2003. p.32. 
presente como virtualidade, potência. Essa recordação do presente é o que dá origem ao "anacronismo formal", procedimento historicizante por natureza, baseado na coexistência de uma forma-passado em um ato presente, sem projeto ou método definidos. Já o "falso reconhecimento" vai originar o procedimento do "anacronismo real", nele o agora se disfarça de um passado já realizado, cronológico, visto como pura repetição.

Os "discursos do fim" (fim da história, fim da arte, fim da política, fim da literatura, etc) são decorrentes do estado de ânimo que acompanha o anacronismo real e estão relacionados à incapacidade de suportar a experiência do possível ${ }^{34}$. O falso reconhecimento do passado conduz à paralisia da ação e da própria história ao apagar a distância entre potência e ato, reduzindo tudo à reprodução de um passado já dado. Este anacronismo real está próximo do que Perniola analisa como o "já sentido", que caracteriza nossa época como "essencialmente estética" ${ }^{35}$, não por algum tipo de relação especial com as artes, mas porque é no plano do sentir que ela exerce seu poder, e não nos campos da ação ou do pensamento. Porém, este sentir não é a experiência interior vivida pelo indivíduo, e sim um sentir anônimo, impessoal e socializado, que vem do exterior e não pertence profundamente a ninguém.

Já a recordação do presente é justamente o que pode nos levar a uma existência plenamente histórica, se for vivida como um ethos, um complexo de costumes, para que não escorregue até seu oposto e tome a aparência de "fim da História", como alerta Virno:

\begin{abstract}
Esto es lo que sucede hoy em día. Frente a la hiperhistoricidad de la experiencia, la ideologia posmoderna se apresura a entornar la cantilena lúgubre y dulzona del déja vù: todo ha sido ya; la historia ha caído "en el orden de lo reciclable"; estamos de todos modos destinados, no importa si por premio o por castigo, a la "rememoración densa, permanente, de todas las figuras de nuestra vida" (Baudrillard); toda acción posee el estatuto y los encantos de una cita. ${ }^{36}$
\end{abstract}

\footnotetext{
${ }^{34}$ Idem. p.56.

35 "A nossa época é estética, porque tudo o que nela é efectual tem de ser marcado a ferro pelo já sentido, porque o sensível e o afectivo se impõem como algo de já pronto e confeccionado que apenas requer ser assumido e repetido". PERNIOLA, Mario. Do sentir. Trad.: António Guerreiro. Editorial Presença, Lisboa, 2003. p.24.

${ }^{36}$ VIRNO, Paolo. Op. cit. p.59.
} 
O "querer fazer" que caracteriza a produção contemporânea se realiza na eleição de formas e referências às quais se devolve potência. Na revista Inimigo rumor, este procedimento está dado desde o início, com a carta de João Cabral e o dístico de Paul Valéry: "Plus élire que lire" 37.

Diante da desorientação e indeterminação de trabalhos artísticos que com total liberdade retornam aos estilos do passado, somos tentados a pensar a época contemporânea como um "neo-ecletismo", no entanto Perniola ressalva:

ecletismo quer dizer, tanto etimologicamente como conceitualmente, eleição em nome de um ideal de arte que se julga dever realizar com cada vez mais proximidade: agora bem, não só nenhum ideal de arte parece hoje impor-se a sensibilidade crítica, como o que caracteriza a situação presente é justamente a impossibilidade de eleger, ou melhor, a perfeita equivalência e reversibilidade das eleições, a multiplicidade das propostas que não se podem reduzir a nenhuma unidade, ou a nenhum horizonte poético e crítico definido ${ }^{38}$.

A reflexão de Perniola sobre a literatura do presente parece estar muito próxima do que Blanchot pensou em seu texto sobre o desaparecimento da literatura. Habitando um espaço que é já seu limite, sua fronteira, a literatura abandona a si mesma e se transforma, apagando distinções entre poema e prosa, literatura e crítica, poesia e filosofia.

Neste sentido, o arquivo das revistas é também ficção ${ }^{39}$, narrativa. $E$ como narrativa do presente, o que ela nos conta não são episódios de uma história linear, mas apenas fragmentos, ruínas do próprio presente que não deixam entrever qual será o próximo capítulo.

A paralisia e a morte que desde Hegel já 'assombravam' a arte e a poesia, podem tomar um outro sentido, muito mais produtivo, com Walter Benjamin e seus

\footnotetext{
${ }^{37}$ Esse dístico está comentado também no ensaio de Maria Lucia de Barros Camargo: "'Plvs élire que lire'- A poesia e suas revistas no final do século XX", publicado em Poesia e contemporaneidade: leituras do presente. Chapecó, Argos, 2001.

38 PERNIOLA, Mario. Enigmas: egípcio, barroco y neo-barroco em la sociedad y el arte. Trad.: Francisco Javier García Melenchón. Murcia: Cendeac, 2003. p.91. (tradução minha)

39 Lembro aqui da revista Ficções, uma espécie de "irmã" de Inimigo rumor dedicada à prosa, foi lançada pela Sette Letras também em 1997, e é editada por Jorge Viveiros de Castro.
} 
conceitos de ruína e origem (o "vir a ser e o declinar" das obras ${ }^{40}$ ), e também com Paolo Virno e a recordação do presente. A teoria que Virno propõe coloca o passado como uma potência virtual, que acompanha, precede e segue 0 ato, 0 circunda. Se em Heidegger, por outro lado, a potência está associada ao futuro, este futuro predomina porque dominado pela morte, é um futuro enquanto fim, de onde se originaria a história. A inversão em Heidegger se fundamenta no fato de que a interrupção da vida nunca é um fato para o que vive, e o aniquilamento que o atinge a cada instante é o que conserva os traços da pura possibilidade ${ }^{41}$, pois o ser que permanece não chega a experimentar a sua realização. $E$ este ser que permanece (o ser-para-morte), segue sendo um poder-ser, diante do passado como um repertório de possibilidades:

\begin{abstract}
"el Ser que permanece escoge a sus héroes". Pero aquel que toma del legado de la tradición "la fuerza silenciosa de lo possible", antes que expuesto a una coacción inapelable, se halla también en condición de tomar libres decisiones (o, al menos, de adoptar comportamientos no prefijados) en la situación presente. Repitiendo y decidiendo, el Ser que permanece manifiesta la propia y auténtica historicidad. ${ }^{42}$
\end{abstract}

Essa "livre decisão" seria mais propriamente uma escolha, conforme a distinção feita por Benjamin no ensaio sobre As afinidades eletivas de Goethe. A decisão, ação que implica uma moral e uma transcendência, é o oposto da eleição que, natural e "apropriada para os elementos", é a química que dá origem à afinidade. Enquanto a decisão pressupõe um indivíduo consciente, capaz de discriminar e decidir conforme uma "razão universal", a eleição, por sua vez, seria o procedimento típico deste sujeito cindido e em devir, do "ser qualquer" ${ }^{43}$ que

\footnotetext{
${ }^{40}$ Conceitos que estão diretamente associados à "literatura do presente", conforme o estudo de Susana Scramim: "As obras que consideraremos portadoras desses estratos de tempo 'presente' serão aquelas que logram selecionar os valores que se encontram formalizados numa economia dos afetos, que não precisamente uma forma, mas antes maneiras de combinar os efeitos do processo de 'vir-a-ser' e extinguir-se das obras." In Literatura do presente: história e anacronismo dos textos. Chapecó: Argos, 2007.

${ }^{41}$ VIRNO, Paolo. Op. cit., p.157.

42 Idem, p.158.

43 "Qualquer é a figura da singularidade pura. A singularidade qualquer não tem identidade, não é determinada relativamente a um conceito, mas tampouco é simplesmente indeterminada; ela é determinada apenas através da sua relação com uma idéia, isto é, com a totalidade das suas
} 
encontramos na literatura do presente, um ser em ato, em relação direta com a potência.

Essas escolhas assim, se produzem como efeito de uma afinidade ou, na duração de um afeto. Conforme a Ética de Espinosa, em estudo de Deleuze, o afeto se origina no contato entre dois corpos, que resulta no aumento ou na diminuição da potência de agir $^{44}$, e estes corpos podem ser pensados como corpos textuais, poéticas. Tal abordagem do afeto e da afinidade interessa por estar diretamente vinculada à potência e à ação. O pathos da escolha, o sentir contido na eleição não corresponde a uma passividade, ao contrário, ele mesmo é ato, aproximação de corpos.

Perniola realiza um estudo aprofundado sobre o sentir que caracteriza a época contemporânea, e propõe como forma de escapar ao "já sentido" que nos torna meros espectadores de nós mesmos, o "fazer-se sentir", em que sujeito e objeto se indiferenciam. Para isso, o autor italiano resgata duas formas de representação da afetividade na antiga Grécia: "a aísthesis, que compreende tanto a percepção como a inteligência" e o "ménos, que tanto compreende o ardor afetivo como o princípio da vontade de ação" ${ }^{45}$.

Este sentir é, por fim, um "querer sentir", ele nasce de uma escolha e se desdobra em uma prática, em "uma ascese no sentido literal e etimológico do termo, que significa precisamente exercício. O sentir é seletivo: somos nós que estabelecemos quais são as portas que devemos abrir ou fechar. Não existe nada de espontâneo nesse processo" ${ }^{46}$. Com isso, a dimensão afetiva torna-se também uma operação intelectual, do mesmo modo que o intelectual passa a ser uma recepção afetiva. Essa experiência do fazer-se sentir está diretamente vinculada ao presente, à atenção constante e à abertura ao imprevisível acontecimento de cada instante.

possibilidades". AGAMBEN, Giorgio. A comunidade que vem. Trad.: António Guerreiro. Editorial Presença, Lisboa, 1993. p.53.

${ }^{44}$ DELEUZE, Gilles. Espinosa: filosofia prática. São Paulo: Escuta, 2002.

${ }^{45}$ PERNIOLA, Mario. Do sentir. Trad.: António Guerreiro. Editorial Presença, Lisboa, 2003. p.101.

${ }^{46}$ Idem, p.103. 


\section{Penhor do futuro}

Em sua reflexão sobre o arquivo, Derrida não define o que seria tal conceito, mas mantém a imprecisão que acompanha o termo, a "impressão" sobre o arquivo, como forma de deixar a porta aberta ao por vir, como "penhor do futuro" ${ }^{47}$. Nesse sentido podemos ler, a partir de Inimigo rumor, outros trabalhos seguindo uma trajetória muito semelhante, como, por exemplo, a revista Cacto. Inicialmente pensada para se chamar "Totem", este nome foi substituído pelo título de um poema de Manuel Bandeira. Editada por Eduardo Sterzi e Tarso de Melo em São Paulo, desde o editorial do seu primeiro número, lançado em 2002, Cacto afirma (forma) o vínculo com sua antecessora:

[...] oferecemos nossas vozes ao diálogo que já se encontra estabelecido em outras publicações atuais, dentre as quais destacamos Inimigo rumor, já em seu $12^{\circ}$ número e agora luso-brasileira, à qual nos sentimos especialmente afins. Felizmente, alguns cactos não precisam de um deserto para crescer. ${ }^{48}$

A nova revista, ao surgir reivindica para si certa 'herança', se colocando na esteira do projeto Inimigo rumor em andamento, publica ainda neste primeiro número uma entrevista com Carlito Azevedo. A proximidade entre estas duas publicações vai além: o projeto gráfico de Cacto é enxuto, também sem dar espaço a ilustrações, em formato-livro, com apenas uma cor na capa; o título da revista é também retirado de um poema; Augusto de Campos é o poeta que inaugura Cacto, com "Faça o que faça".

${ }^{47}$ DERRIDA, Jacques. Mal de arquivo: uma impressão freudiana. Trad.: Claudia de Moraes Rego. Rio de Janeiro: Relume Dumará, 2001., p.31.

${ }^{48}$ Cacto $\mathrm{n}^{\circ} 1$, editorial, p.4. 
Por outro lado, Cacto é um desdobramento da antiga Monturo, também editada por Tarso de Melo ${ }^{49}$. Observo, como outro ponto de contato, que nos quatro números publicados até 2004 os textos de Leminski não apareceram.

O diálogo com a poesia portuguesa, que Inimigo desenvolveu no período em que foi uma publicação luso-brasileira, parece ter repercutido na cena da poesia e da crítica de poesia, como se pode ver com o dossiê "Vozes da poesia" publicado pela revista Cult em 2006. Com organização de Eucanaã Ferraz, o dossiê é composto por cinco ensaios dedicados à poesia brasileira contemporânea e um último intitulado "Poesia portuguesa do século 20", escrito pelo português Gastão Cruz, um dos grandes colaboradores de Inimigo rumor no período em questão. E ainda, o texto do organizador que abre o dossiê inicia com epígrafe do poeta português Ruy Belo, justamente o homenageado no número 15 de Inimigo rumor em 2003, e que até então era relativamente desconhecido no Brasil, além de não haver edição brasileira do trabalho deste poeta morto em 1978.

Outra herdeira de Inimigo é a recém lançada Modo de Usar \& Co., também uma publicação de poetas. Angélica Freitas, Fabiano Calixto, Marília Garcia e Ricardo Domeneck, todos jovens com menos de 40 anos, possuem em comum o fato de terem iniciado a publicação de seus poemas em Inimigo rumor, que se desdobra na coleção de livros organizada por Carlito Azevedo Ás de colete, uma parceria das editoras Cosac Naify e 7 Letras, em que os quatro publicaram seus livros. O título da coleção é retirado do livro de poemas Ás de colete de Zuca Sardan, publicado em 1994, pela editora da Unicamp.

Nesta mesma coleção é publicada a reunião de poemas da portuguesa Adília Lopes, também organizada por Carlito e intitulada apenas Antologia. No mesmo movimento, quando Carlito Azevedo reúne sua produção em antologia, em 2001, dá a ela o título de Sublunar, retirado do poema de Adília, presente na

\footnotetext{
${ }^{49}$ Ambas as revistas apresentam publicidade da Alpharrabio Livraria.
} 
epígrafe do livro: "Falo de ovos estrelados, coisa caricata, suja,/ sublunar, como as maminhas/ e o cão animal que ladra." ${ }^{50}$

Sobre esta trama de contatos e afetos poéticos ainda pouco pode ser dito, considerando seu caráter movente, em movimento. Fica uma imprecisão, uma impressão, aquela mesma que permanece no conceito de arquivo. A revista enquanto narrativa, ficção sobre a poesia, ou então, como um poema, elaborado no contato-costura dos fragmentos que compõem este arquivo, efeito do "querer fazer", se lança a desdobramentos e outras configurações sempre imprevisíveis. Devolvendo potência a atos já realizados, estes desdobramentos são a porta que une e separa, a garantia de um por vir.

${ }^{50}$ A aproximação entre as poéticas de Carlito Azevedo e Adília Lopes é destacada por Franklin Alves Dassie, no ensaio "Vacas na aula de arte: a Antologia de Adília Lopes". In: CAMARGO, Maria Lucia de Barros; PEDROSA, Célia (Orgs.). Poéticas do olhar e outras leituras de poesia. Rio de Janeiro: 7Letras, 2006. 


\section{REFERÊNCIAS}

AGAMBEN, Giorgio. El hombre sin contenido. Trad.: Eduardo Margaretto Korhmann. Barcelona, Ediciones Áltera, 1998.

A comunidade que vem. Trad.: António Guerreiro. Lisboa: Editorial

Presença, 1993.

. Profanaciones. Trad.: Flavia Costa; Edgardo Castro. Buenos Aires:

Adriana Hidalgo, 2005.

ALENCAR, João Nilson Pereira de. Políticas culturais - antologias: a constituição de cânones literários no modernismo tardio. UFSC, Florianópolis, 2007. [Tese de doutorado].

ANDRADE, Ana Luiza et al (orgs.). Leituras do ciclo. Florianópolis: ABRALIC: Chapecó: Grifos, 1999.

BENJAMIN, Walter. Origem do drama barroco alemão. Trad.: Sérgio Paulo Rouanet. São Paulo: Brasiliense, 1984.

"Historia y coleccionismo: Eduard Fuchs" in Discursos interrumpidos I. Trad.: Jesus Aguirre. Barcelona, Planeta-Agostini. 1995. p.89-135.

. Dos ensayos sobre Goethe. Barcelona: Editorial Gedisa S.A., 1996.

. "O colecionador" in Passagens. (Org.: Wille Bolle) São Paulo: IMESP, 2006. p.237-246.

BLANCHOT, Maurice. O livro por vir. Trad.: Leyla Perrone-Moisés. São Paulo: Martins Fontes, 2005.

BORGES, Jorge Luis. "A postulação da realidade" in Obras completas: 1923-1949. Buenos Aires: Emecé editores, 2007. p.253-258. 
CAMARGO, Maria Lucia de Barros; PEDROSA, Célia (Orgs.). Poéticas do olhar e outras leituras de poesia. Rio de Janeiro: 7Letras, 2006.

. Poesia e contemporaneidade: leituras do presente. Chapecó, Argos, 2001.

DELEUZE, Gilles. Espinosa: filosofia prática. São Paulo: Escuta, 2002.

DERRIDA, Jacques. Mal de arquivo: uma impressão freudiana. Trad.: Claudia de Moraes Rego. Rio de Janeiro: Relume Dumará, 2001.

MACIEL, Maria Esther. A memória das coisas: ensaios de literatura, cinema e artes plásticas. Rio de Janeiro: Lamparina editora, 2004.

MELO NETO, João Cabral de. In Inimigo rumor. Rio de Janeiro, Sette Letras, 1997, nº 1.

PERNIOLA, Mario. Enigmas: egípcio, barroco y neo-barroco em la sociedad y el arte. Trad.: Francisco Javier García Melenchón. Murcia: Cendeac, 2003.

Do sentir. Trad.: António Guerreiro. Lisboa: Editorial Presença, 2003.

SCRAMIN, Susana. Literatura do presente: história e anacronismo dos textos. Chapecó: Argos, 2007.

VIRNO, Paolo. El recuerdo del presente: ensayo sobre el tiempo historico. Trad.: Eduardo Sadier. Buenos Aires, Paidós, 2003. 